\title{
Research on the Difficulties in Rural Renovation Through Art Intervention Under the Background of Rural Rejuvenation and Countermeasures
}

\author{
Wei Zhong ${ }^{1, a}$, Wang Xueqin ${ }^{2, b^{*}}$ \\ ${ }^{1}$ School of Arts, Nanjing University Pujiang College, Lishui, Nanjing, Jiangsu, China \\ ${ }^{2}$ School of Arts of Sanjiang University, Yuhua, Nanjing, Jiangsu, China \\ a107596961@qq.com \\ $b^{*}$ wxqt_108@163.com
}

\begin{abstract}
The rural renovation effort has been continuously deepened throughout China since the implementation of the rural rejuvenation strategy and has tapped the vitality of the countryside after integrating the resources and forces on all fronts. However, the homogenization phenomena of rural renovation and development hindering the growth of all villages urgently need scientific research and countermeasures. The paper analyzes the present situation of rural development to show the priorities to rural rejuvenation attached by the Communist Party of China and the country, illustrates and enumerates the successful examples of rural rejuvenation and the modes of rejuvenation at present, discusses the general requirements, objective and subjective factors and interaction effects, brings forth the difficult factors affecting rural rejuvenation through art and proposes the countermeasures for rural development through art intervention. It points out that China's rural rejuvenation effort should pay attention to the thinking of "art intervention", and takes the principal line of crowd behaviors featuring "focus on villagers, government leadership, artists' guidance, subject direction and social participation" to overcome the barriers between the subjects and objects of the subjective and objective factors, foster the sustained driving forces of "influencer" and "new media" etc and effectively overcome rural homogenization. Considering the difficulties of rural rejuvenation through art intervention and based on typical case analysis, the paper puts forward countermeasures from the perspectives of rural development process, the prospects of economic capacity, the feasibility of art intervention with countryside and rural development, provides a scientific basis for rural art, fundamentally solves the difficulties of rural development, taps the endogenous impetus of rural development and realizes overall rural rejuvenation.
\end{abstract}

Keywords: art intervention, rural rejuvenation, development difficulties, crowd behaviors, research on countermeasures

\section{乡村振兴背景下艺术介入乡村改造困境与对策研究}

\author{
魏忠 $1, a$ 王雪芹 $2, b^{*}$ \\ ${ }^{1}$ 南京工业大学浦江学院艺术学院, 溧水, 南京, 江苏, 中国 \\ ${ }^{2}$ 三江学院艺术学院, 雨花, 南京, 江苏, 中国 \\ a107596961@qq.com \\ b*wxqt_108@163.com
}

\section{摘要}

自推动乡村振兴战略实施以来, 我国各地乡村改造不断深化, 在融合各方资源与力量后, 激发了乡村自身活力, 但乡村改造与发展的同质化现象、“千村一面”问题亟待科学研究并提出对策。本文先梳理有关乡村发展脉络, 以体现党和国家对乡村振兴关注度与重视程度, 说明我国乡村经济发展前景并列举目前乡村成功案例及其采取 
的振兴模式, 探讨乡村振兴总要求主客体因素以及相互影响关系, 提出艺术乡村振兴困境因素, 指出艺术介入 乡村发展对策。指出我国乡村振兴应注重 “艺术介入” 的助推思想, 围绕 “村民为主、政府领导、艺术家指导、 学科指引、社会参与” 人群行为脉络作为主线, 以克服主观因素与客观因素的主客体之间壁垒, 生成 “网红”、 “新媒体” 等持续性的助推力, 可以有效克服乡村同质化与 “千村一面” 问题。考虑到艺术介入乡村振兴困境, 基于典型案例分析, 从乡村发展进程、经济产能前景、艺术介入乡村可行性、乡村发展等角度提出对策措施, 为乡村艺术提供科学依据, 从根本上解决乡村发展内外困境并激活乡村发展内生的动力, 从而实现全面实现乡 村振兴。

关键词: 艺术介入; 乡村振兴; 发展困境; 人群行为; 对策研究

\section{1. 前言}

改革开放至今, 我国经济得到快速发展, 城镇一 体化的差距越来越小, 而城乡发展出现了不平衡、贫 富差距越来越大等现状。党和国家领导人面对这种问 题, 高瞻远瞩。习近平总书记于 2017 年 10 月, 在党 的十九大上作出重大决策部署—— “实施乡村振兴战 略”。2018 年 2 月, 中央一号文件《中共中央国务 院关于实施乡村振兴战略的意见》正式颁布。文件贯 彻党的十九大精神, 在我国国情、农情的基础上, 规 定了实施乡村振兴战略的指导思想、目标任务和基本 原则, ${ }^{[1]}$ 进一步为乡村振兴总要求确定了方向。如今, 我国 “美丽乡村”、“网红乡村” 等成功案例举不胜 数, 但也存在盲目追求乡村经济发展, 过度改造以及 同质化现象, “千村一面” 随处可见。针对相应问题, 国内不少专家、学者纷纷提出个人看法并努力进行实 践项目, 如: 2011 年, 左靖开始在安徽黟县进行的 “碧山乡建”、中国美院的王澍对浙江富阳文村进行 改造、同济大学的娄永琪带领学生在上海崇明岛开展 的 “设计丰收”, 以及五邑大学的谭金花在开平碉楼 之乡开展的 “仓东计划” 实践。2016 年开始, 以渠 岩为首的专家团队主导了艺术介入乡村复兴实践的 “青田计划”。艺艺术介入乡村复兴当中, 给当下乡 村经济发展与乡村振兴提供了很好的借鉴与参考。然 而, 在乡村复兴实践过程中, 乡村艺术也面临着诸多 困境, 需要正确面对并有妥善的对策解决方案。

\section{2. 乡村振兴的进程脉络与研究}

乡村振兴与发展需要从时空层面进行深入探讨。 从时间层面上, 乡村发展进程主要是:

上世纪 $20 \sim 30$ 年代 “乡村文化振兴” : 当时中 国乡村出现了前所未有的危机。在此背景下, 乡村复 兴潮流汹涌, 有识之士认为, 要从中国传统文化和现 代西方文化中汲取资源, 推动乡村复兴。 ${ }^{[3]}$

上个世纪中叶, 提出社会主义新农村。2005 年
10 月, 北京召开了十六届五中全会, 在会上明确指 出了我们党和国家在经济建设方面的重要任务主要 是社会主义的新农村建设; 在 2007 年 10 月份, 我们 党的十七大上提出了统筹发展的新目标; 在“十一五” 时, 由于各个省市在计划制定后坚决的实施与贯彻, 这一目标已取得阶段性成果。

2008 年建设美丽乡村: 浙江省以 “中国美丽乡 村”计划把安吉县打造成为具有示范与代表性的地方。 到 2013 年的时候, 习近平对鄂州市长港镇峒山村进 行全面的考察, 提到了农村建设与城镇发展一体化的 发展目标。

2016 年 11 月底, 习近平总书记提出 “绿水青山 就是金山银山”的要求。提出要始终牢记“五位一体” 总体发展布局, 并将 “四个全面” 的总体战略布局牢 记在心中, 人民群众要将青山绿水看作发展的金山银 山，保护好自然资源。

2017 年振兴乡村: 党的十九大上, 习总书记首 次明确振兴乡村和 “三农” 发工作, 是在现有的基础 上进行全面分析后, 结合国家现有发展阶段特征, 为 发展我们党和国家的事业有针对性的提出的决策。全 党始终将解决 “三农” 问题当作工作的核心内容, 也 加大力度改变农业、农村的各项落后面貌, 不断填补 农村建设小康社会中的不足, 并不断延长“四化同步” 的发展。

空间层面上，1980-2021 年间，与 “乡村” 有关 的乡村振兴关键词出现频率多达 28025 次, 占 $41.88 \%$; 乡村振兴战略关键词 16063 次, 占 $24 \%$, 合计 $65.88 \%$, 如图 1 所示。另外, 在 30 多年当中, 先后有董进智、 潘鲁生、王巍、杨吉华等数十名专家学者积极围绕乡 村振兴总体要求, 进行有意义的研究、人才培养、实 践尝试等, 并分享了与乡村振兴有关的科研成果。 


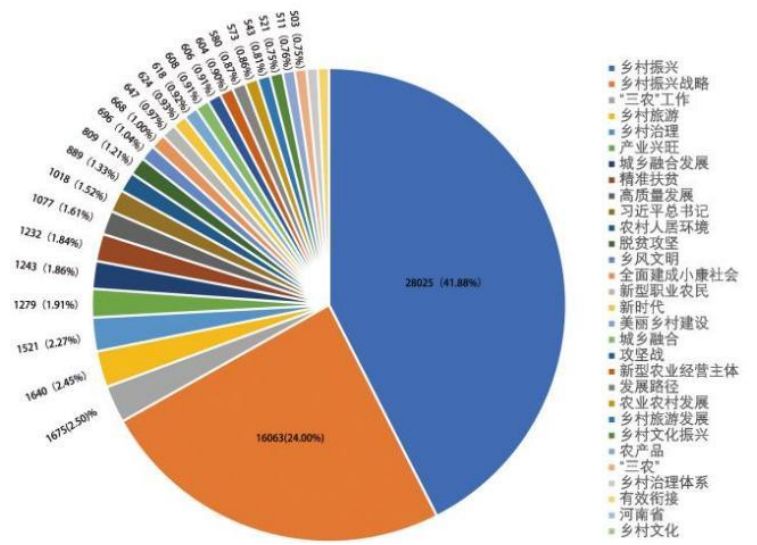

图 1 关于乡村振兴关键词与频率饼状图, 来源知网

通过梳理相关的参考文献可以发现, 有的则是从 艺术介入乡村实践案例分析, 指出当代艺术可以成为 乡村振兴的路径; 有的则是从造物设计、匠心文化、 文化保护和传播等方面指出艺术独特优势, 并探索艺 术介入乡村设计的策略; ${ }^{[4]}$ 也有学者提出 “艺术乡建” 理念; ${ }^{[5]}$ 还有学者提出乡村规划中 “五态融合模型”, 在物质更新层面, 提出了从村庄宏观结构控制到村庄 中观空间组织, 再到节点微观环境设计的技术体系。 的技术体系。 ${ }^{[6]}$ 另外, 有专家提议利用主流媒体的传 播模式, 对乡村振兴进行宣传报道。对研究结果进行 分析, 相应学者专家给出了个人的具有建设性的理念 与实践成果, 涉及到乡村景观、乡村规划、艺术介入 理念等。但从研究观点、研究内容、研究角度等来看, 仍存在 “单一化” 或 “碎片化” 问题。笔者认为, 一 方面需要借鉴乡村改造与乡村产业成功的案例, 汲取 同质化严重、改造过渡, 造成 “千村一面” 负面 典型的教训, 另一方面也需要通过科学合理分析, 找出解决问题的对策与方法。

\section{3. 乡村振兴的案例与分析}

近年来, 我国乡村旅游呈现出了一个热点态势, 无论是从参与乡村旅游的人数上, 还是从参与乡村旅 游的规模上, 都出现了持续增长的良好势头。如表 1 所示, 2011-2019 年, 我国休闲农业和乡村旅游接待 人数稳步增长, 从 4 亿人增至 32 亿人。受突如其来 的新冠疫情影响, 2020 年我国乡村旅游发展暂缓, 但从 5 月份开始各地乡村旅游有序重启, 2020 年 1-8 月中国休闲农业和乡村旅游接待人数为 12 亿人, 同 比下降 $62.5 \%$ 。

表 $12011-2020$ 年我国休闲农业和乡村旅游接待人 数情况, 来源官研天下

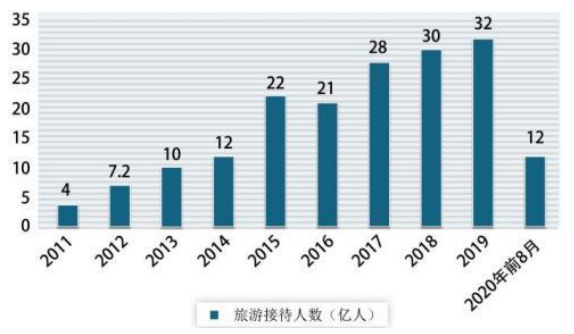

此外，我国休闲农业和乡村旅游营业收入明显增 加, 如表 2 所示, 从 2015 年的 4400 亿元发展至 2019 年的 8500 亿元。其中， 2019 年中国休闲农业和农村 旅游营业收入占旅游收入的 $14.2 \%$ 。

表 2 2015-2019 年我国休闲农业和乡村旅游营业收 入及在整体旅游收入中的比例, 来源官研天下

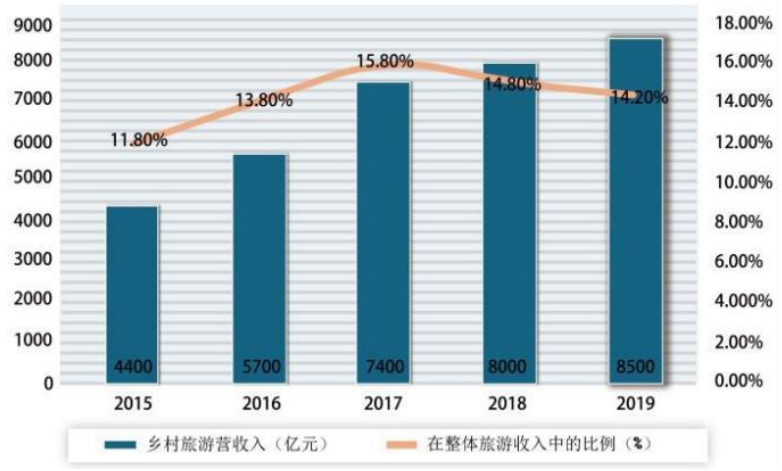

陕西省袁家村采用 “民俗网红” 模式，成功打造 “关中印象体验地” 和 “陕西非遗小吃与技能学习体 验村”, 该村拥有 3000 多家经营者, 年接待游客超 过 500 万人次, 旅游收入超过 5 亿元, 在网红中形成 名副其实的 “打卡” 场所。 ${ }^{[8]}$ 浙江乌村采用 “乡愁网 红” 模式, 自 2016 年试运行以来, 吸引了无数媒体 机构和游客的关注, 成为代表全国最高水平的乡村旅 游发展项目, 采用 “CCO” 服务模式, 精心策划和组 织各类文化活动, 提供陪伴式服务。 ${ }^{[9]}$ 如图 2 所示, 管理部门充分结合当地人文地理优势, 举办 “艺术文 化节”, 引进新媒体传播媒介, 诚邀有名的明星, 黄 否、何炅、赖声川在微博晒出 “乌镇出没” 的痕迹, 在乌镇录制爱奇艺《戏剧新生活》。

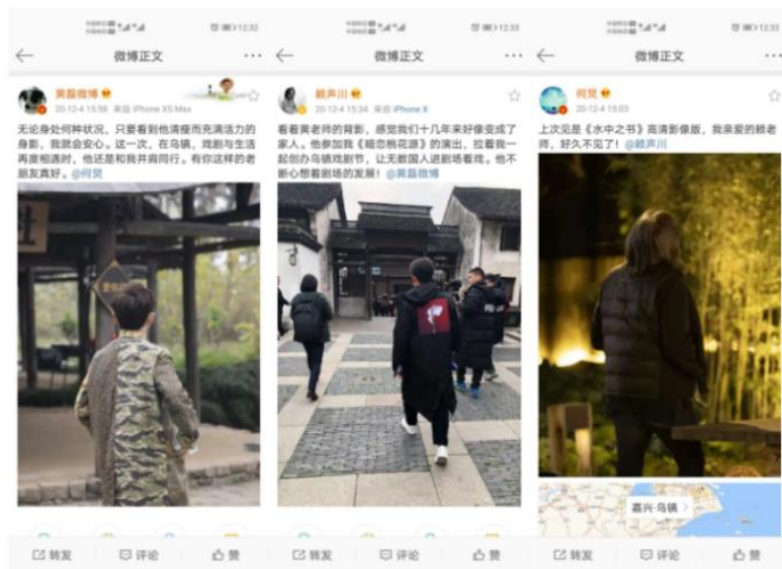

图 2 与爱奇艺《喜剧新生活》有关微博截图, 来源 乌镇官网

浙江莫干山的 “民宿网红” 模式。四季变换, 造 就莫干纯天然自然景观: 推窗见山, 竹林环绕, 鸟叫 蝉鸣, 鸡犬相闻, 追忆似水流年, 看山看水看云看日 出, 优哉游哉; 莫干山是德清民宿经济日益繁荣的缩 影。据统计, 2017 年, 德清县接待以民宿经济为主 
的乡村旅游游客 658.3 万人次, 同比增长 $17.9 \%$, 实 现直接经营收入 22.7 亿元, 同比增长 $36.7 \%$ 。

现如今, 莫干山已经聚集了 550 多家民宿, 其中精品民宿有 56 家。 ${ }^{[10]}$ 相应的网红乡村实践案 例启发我们: 第一、借助当地特点与优势打造文 化主题, 激发乡村内生动力; 第二, 对应激励政 策与配套措施需要同步推进, 如江苏省南京 “傅 家边农业科技园”，其有机草莓种植基地，自 2013 年以来, 政府每年投资 1000 多万元建设乡村景观, 销售额同比增长约 3\%; “11]第三、实用便利的经营管 理模式, 如浙江乌镇的 “一价全包” 套餐体验模式、 乌村的 “CCO” 服务模式等, 有助于全盘助推乡村产 业发展, 提升经济水平, 聚集各种发展要素, 改变城 市的单向 “虹吸效应”; 第四、合理的经营时间跨 度, 进一步拓宽了经营收入渠道, 延长了乡村产 业链营销跨度, 从而增加了经济收入, 例如: 浙 江莫干山采取春季 “踏青游” ; 夏季 “避暑游”; 秋季 “登高游” ; 冬季 “烂漫游”。2018 年, 仅春 节期间, 莫干山就接待国内外游客 17.83 万人次, 实 现旅游收入近 2 亿元。

\section{4. 关于乡村振兴难点的思考}

如今, 我国各地充分按照 “实施乡村振兴” 战略 制定符合自身发展的实施纲领, 按部就班推进乡村发 展。“产业兴旺、生态宜居、乡风文明、治理有效、 生活富裕”深化了乡村建设细节, 构建了“五位一体” 系统, 分别体现了乡村的生产空间、生态空间、文化 空间、生活空间、物质空间。这种分类既符合农村的 本质属性, 又符合乡村振兴战略总体要求中的四个要 求。

虽然, 实施乡村战略已经明确, 但经济发展来体 现产业兴旺绝非一朝一夕可以实现了的, 乡村建设存 在几个明显问题:一是产业单一, 活力不足。二是环 保观念不强, 青山到金山银山的价值转化率低。三是 刻板印象依然存在, 行政治理效果有限。四是秩序弱 化, “自发” 动员乏力。五是文化资源薄弱, 收入渠 道狭窄。相应问题归根结底在于: 没有充分发挥 “艺 术” 魅力去分析问题并提出科学合理的解决方案。这 里的 “艺术” 是社会学意义上的当代艺术实践, 而不 是视觉审美范畴的艺术形式。[12]

通过文献资料、对实际成功案例的调查与分析, 笔者认为当前中国乡村振兴研究, 应当从艺术层面介 入乡村振兴, 但在以下几个方面值得反思。

从思维模式上, 不论是从 “乡村网红” 模式、“主 流媒体介入乡村” 模式, 还是 “艺术乡建” 理念, 都 需要认真探究乡村本身属性, 研究乡村文化内涵。当 研究对象主客观因素明确后, 才能实施后期步骤。乡 村振兴战略的五个要求, 彼此相辅相成, 缺一不可。 在思维层面上, 需要注意的是: 一、选择问题, 也就 是 “兴村先兴人”, 还是兴村先兴产业经济。两者理 性选择, 直接关乎到乡村振兴战略实施问题; 二、改
造理念问题，仍然沿用 “形式服从功能” 理念, “三 观”（宏观、中观、微观）规划理念。只有当主客观 因素合理区分, 才能正确选择; 三、参与问题, 也就 是乡村振兴参与人群问题。面对我国幅员辽阔、民族 多、乡村数量大、发展基础不同、特点有别等诸多因 素, 不同的乡村需要哪些人群参与到乡村改造当中, 也需要认真思考; 四、营销策略问题

实践方法上, 需要进一步明确实施路径。当前乡 村振兴的实践方法大多侧重于乡村物质空间的实施, 即静态空间层面, 而忽视了乡村文化的 “生存状态” 精神文明层面。多数乡村改造中, 没有协调好两者之 间的关系, 造成改造过渡, 形式统一、内容无差别的 问题。上世纪初, “形式服从功能” 理念, 指引了设 计发展, 改变了人们的生活环境, 提升了人们的生活 水平。但是, 该理念是着重解决二战后, 各个国家面 对的是百废待兴的社会问题, 需要有科学合理的实施 途径, 解决社会矛盾。进入新时代, 我国社会主要矛 盾已不再是人民对物质生活的追求, 转变为人民日益 增长的美好生活需要与不平衡不充分的发展之间的 矛盾。矛盾的转化, 必定需要与时俱进的实施路径。

从艺术介入乡村实践上, 是从基层建设开始, 还 是从宏观层面介入。也就是说, 艺术乡建如何破解“单 一化”局限或片面性问题。不少学者专家提到“艺术” 对乡村振兴的作用与意义, 也有学者过度夸大艺术作 用, 主张由艺术主导乡村振兴。当我们冷静下来思考 问题时候, 任何介入乡村方式都应进行理性分析, 选 择正确的 “思考点” 与 “切入点”。

\section{5. 艺术介入乡村振兴对策选择}

对于乡村振兴困境研究回顾与反思, 不难发现, 目前相应处理乡村发展困境仍只注重表面上, 乡村深 层次问题还处于探索阶段, 并没有充分结合乡村自身 特点与文化背景等因素, 基础研究不够深入, 实践范 式趋向城市化模式。另外, 研究团队主体不够厚实, 过多依赖于设计专业人员或某一领域专业人士。故此, 我们应结合成功案例并在吸取改造教训基础上, 研究 乡村振兴对策。

\section{1. 明确艺术介入乡村振兴的助推思想}

新时期的乡村改造已不是单纯的乡村规划、微更 新的实质性举措, 更多地需要具备持久性的不断提升 乡村面貌与产业价值的主导思想。促进乡村振兴面临 的主要难点在于 “人心”, 乡村能否发展、能否持续 发展, 关键是乡民思想是否统一, 村干部能否凝聚村 民共同改变村落现状, 提升生活质量, 增加收入。20 世纪 80 年代, 徐启斌推广 “要想富, 先修路” 思想, 如果单靠个人行为无法改变当时贫困现状。2014 年 10 月 24 日, 国家主席习近平在人民大会堂会见出席 筹建亚洲基础设施投资银行备忘录签署仪式的各国 代表时, 提出 “要想富、先修路、人心齐、泰山移” 思想, 进一步说明集体精神的作用, 该要求也能诠释 
乡村振兴环节中从思维模式到实践过程。故此, 必须 解放思想, 实事求是, 明确艺术介入乡村振兴的主推 思想，究其原因在于：

1）艺术手段作为社会学层面实践性质相较于行 政要求更利于村民接受。由于村民存在固化思维定式, 在行政规定触探到他们底线时候, 容易发生抵触情绪。 而艺术手段灵活, 可以充分结合村民整体意愿, 弹性 实施要求。对于乡村振兴来说, 首要任务就是村民的 “思想振兴”。

2) 艺术语言是艺术家与欣赏者交流的美学介质, 以直观视觉感受传达信息, 交流顺畅。乡民可以通过 艺术了解环境 (建筑外观、街道、景观等), 感受艺 术家的意图, 了解善意并产生思想上 “共鸣” , 有助 于形成合力。

3) 艺术可以糅合多方力量, 化解不利因素, 形 成共性的促进作用。乡村振兴不是单方面行为举动, 需要形成 “村民为主、政府领导、艺术家指导、学科 指引、社会参与” 人群行为脉络, 激发乡村治理主体 的内源动力, 突出发挥乡村治理中人的积极作用。同 时, 在研究内容深厚的基础上, 协助政府持续引导与 扶持乡村振兴; 社会责任感可以更有效地检验乡村发 展成果, 并促进乡村产业发展。

\section{2. 构建合理研究框架体系}

如图 3 所示, 通过对 “乡村振兴战略总体要求” 进行梳理, 可以看出 “五位一体” 体系对应的空间系 统。生活空间对应生活富裕, 生产空间对应了产业兴 旺, 两者与经济发展关联度高; 环境空间对应治理有 效, 生态空间对照生态宜居, 涉及到环境工程、艺术 设计等领域; 文化空间对应乡风文明。特别要强调的 是, 空间系统中的 “环境空间” 包含了 “人文环境” 与 “自然环境”。人文环境涉及到乡村文化传承与发 展命脉, 是不以主观因素而转移或改变; 自然环境体 现了乡村现有面貌与现状, 需要主体观察并作出合理 判断加以改造。

根据艺术介入乡村振兴助推思想, 涉及到艺术改 变乡民主体思维定式、艺术家正确指导的深度、社会 参与度等, 对乡村经济发展与环境改造客体的程度会 产生不同的影响。“介入程度” 可以看作 “介子” 因 子, 当介子因子参与度高, 对主客体会带来较高影响; 当介子因子参与度偏低, 主客体相互作用与影响就会 下降, 从而直接影响到空间系统, 最终决定乡村振兴 成败。我们相信, 构建本研究框架体系便于有针对性 地介入主客体改造当中。通过解放乡民思想, 必能与 其他力量形成合力, 共同促进乡村经济发展、提高环 境质量。

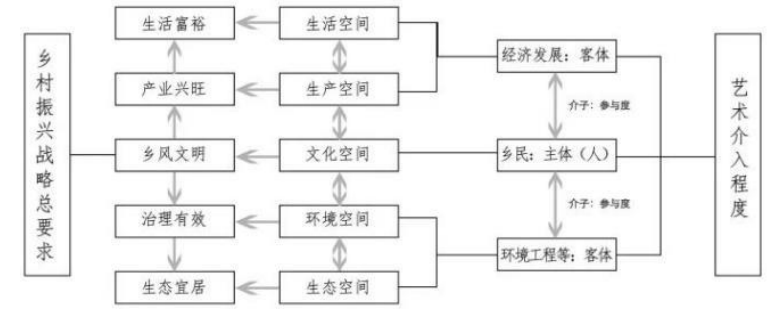

图 3 艺术介入乡村振兴战略研究框架体系, 来源本 人绘制

\section{3. 乡村改造要点}

乡村改造需要从宏观、中观以及微观层面进行权 衡把握改造幅度与力度。在艺术助推思想指引下, 整 合具有发展潜力村落信息, 对乡村客体宏观规划可以 设定短期、中期与长期目标, 确定乡村持续性的发展 链, 对产业链、生态链等有积极促进作用。

中观层面上, 需要对根据乡村文化背景、人文背 景、环境背景等进行充分研究分析, 明确乡村人群行 为脉络为主线, 对主体人群需求进行有针对性的分析。 根据马斯洛需求层次理论内容将人的需求从低到高 依次分为生理需求、安全需求、社交需求、尊重需求 和自我实现需求五种需求, 根据利益相关群体的选择 应坚持多样性原则, 至少包括以下 4 类: 活跃群体、 资源群体、专业群体、弱势群体 ${ }^{[13]}$ 。此外, 还需要确 定村域结构关系、落实乡村空间组织方式。城市中已 经推行 “社区网格化” 管理模式, 这种行政手段对乡 村发展与管理同样具有参考价值。当然, 在确定乡村 振兴发展前, 政府应制定人群协调管理机制, 采用艺 术介入思维实现 “区域一乡村一乡民” 的沟通便捷关 系网。

在微观改造层面上，依据此前准备工作，进一步 细化乡村各个改造细节, 介入艺术形式改造作用。同 时，充分发挥“网红”、新媒体、自媒体等媒体平台， 组建由乡民代表、政府协调者、艺术家、设计师、学 者、知名人物等研究团队参与到乡村改造当中, 破解 一时兴起乡村改造后, 缺少连续性、长效性促进措施 的问题, 形成成员轮流介入的 “雁阵效应” , 持续给 乡村带来产业利润，增加经济收益。

\section{6. 结语}

从上世纪 20～30 年代到 21 世纪新时代, 我国围 绕 “乡村” 发展历经了一百年左右。从早期 “乡村文 化振兴” 到 “乡村振兴战略” , 乡村发展倾向性已经 有所不同, 产生了针对乡村振兴有关的研究成果, 但 多局限于客观环境与视觉层面。虽然 “网红效应” 对 乡村发展起到较好的促进作用, 但持续性效果仍需要 面对的现实问题。与此同时，乡村同质化现象、“千 村一面” 问题还没有改观。因此，本文基于艺术介入 乡村振兴助推思想, 分清主客体在乡村改造中的作用 于扮演的角色。并对乡村采取宏观、中观与微观研究 层次, 并以人群行为脉络为主线, 强调对乡村改造中 
人主导作用, 以艺术糅合状态介入乡村物质形态的改 造升级, 有效促进第一产业与第二第三产业协同发展, 以推动乡村有序渐进, 从而实现乡村振兴总要求。

\section{基金项目}

江苏省教育厅高等学校哲学社会科学研究项目 《乡村振兴背景下情感化设计介入乡村改造研究》 （编号：2020SJA2246）的阶段性成果之一。

\section{REFERENCES}

[1] Zhao Zhizhi \& Yan Ying.(2020) Zhejiang satellite TV's communication mode and development strategy of serving rural revitalization China Radio and television Journal (01), 35-37+ 106 .

[2] Mei Zeying \& Liu Yi. (2020) Qingtian plan -- the path and experience of art intervention in Rural Revitalization Art observation (07), 67-68.

[3] Li Chaoyang \& Wang Dong.(2019) New thoughts on rural environmental design from the perspective of cultural revitalization Art Design Research (04), 69-73.

[4] Teng Xuerong \& Song Yujing. (2021) Research on the strategy of art intervention in rural design under the background of Rural Revitalization Journal of Beijing Architecture University (01), 60-66.

[5] Cai Anning . (2021) Research on the strategy of "art township construction" under the background of Rural Revitalization China's collective economy (14), 4-5.

[6] Zhou Jun, Wang Juan \& Chen Qianhu.(2019) Transformation and development of rural planning under the background of Rural Revitalization -- a case study of xuexiazhuang village, Pujiang County, Zhejiang Province Modern urban research (07), 2-7.

[7] Observation and Research Report network. (2021) analysis report on China's rural tourism market in 2021 - Research on market status and development opportunities

$\mathrm{CN}$ http://baogao.chinabaogao.com/lvyou/5292605292 60.html.

[8] Fan Hua \& Cui Hao. (2019) The design strategy of high-quality demonstration village under the network red economy -- Taking the characteristic style transformation of Jiaxu village, bayou village, Wucun Town, Tianyang County, Guangxi as an example Planner (19), 78-82.

[9] Wu Tsuen. (2019) originated from Wucun CN http://www.wuzhenwucun.com/liaojiewucun/yuanq iwucun.html.
[10] Moganshan national scenic spot. (2013) Moganshan, a place you must go in your life $\mathrm{CN}$ http://www.mogan-mountain.com/.

[11] Zhang Yuqing \& Zhou Wuzhong. (2019) On the promotion of rural landscape to rural revitalization Decoration (04), 33-37.

[12] Chen Jiong. (2021) Research on the strategies and methods of art revitalizing the countryside Journal of Renmin University of China (02), 163-172.

[13] Liu Jiayan.(2009) social planning in urban planning: theory, method and application. Southeast University Press, Nanjing. pp.95; 102. 